This item was submitted to Loughborough's Research Repository by the author.

Items in Figshare are protected by copyright, with all rights reserved, unless otherwise indicated.

\title{
Lesbian, gay, bisexual and transgender psychologies
}

PLEASE CITE THE PUBLISHED VERSION

http://dx.doi.org/10.1002/9781118663219.wbegss137

\section{PUBLISHER}

(c) John Wiley \& Sons, Ltd.

\section{VERSION}

AM (Accepted Manuscript)

\section{PUBLISHER STATEMENT}

This work is made available according to the conditions of the Creative Commons Attribution-NonCommercialNoDerivatives 4.0 International (CC BY-NC-ND 4.0) licence. Full details of this licence are available at: https://creativecommons.org/licenses/by-nc-nd/4.0/

\section{LICENCE}

CC BY-NC-ND 4.0

\section{REPOSITORY RECORD}

Peel, Elizabeth, and Damien Riggs. 2019. "Lesbian, Gay, Bisexual and Transgender Psychologies”. figshare. https://hdl.handle.net/2134/22342. 
Peel, E. \& Riggs, D.W. (2016) Lesbian, gay, bisexual, transgender psychologies. The Wiley Blackwell Encyclopedia of Gender and Sexuality Studies. (pp. 1-6) London: John Wiley. doi: 10.1002/9781118663219.wbegss137 (C) Cite Published Version, URL: http://onlinelibrary.wiley.com/doi/10.1002/9781118663219.wbegss 137/abstract

\section{Lesbian, gay, bisexual, and transgender psychologies}

Elizabeth Peel, Loughborough University, UK

Damien W. Riggs, Flinders University of South Australia, Adelaide

ABSTRACT: Lesbian, gay, bisexual, and transgender (LGBT) psychology is the current term used to refer to what was previously known as the affirmative field of lesbian and gay psychology, which developed from the late 1960s onwards. This field of psychology is closely aligned to the psychology of sexualities, but with a specific focus on non-heterosexual and/or non-gender normative people. The term LGBT psychology signals a more unitary field than LGBT psychologies, the latter highlighting a multiplicity of psychological perspectives and also discrete bodies of psychological knowledge that focus on either lesbian, gay, bisexual, or transgender identities and topics. The epistemological frameworks and research methods utilized within the field of LGBT psychology differ between countries. In North America (and particularly the United States), positivist empiricism informed by liberal humanism is the dominant framework in this field (as with psychological research more generally). In Europe and in Australasia, by contrast, LGBT psychological research is commonly more aligned with post-positivist and critical psychological traditions such as social constructionism.

Lesbian, gay, bisexual, and transgender (LGBT) psychology is the current term used to refer to what was previously known as the affirmative field of lesbian and gay psychology, which developed from the late 1960s onwards. This field of psychology is closely aligned to the psychology of sexualities, but with a specific focus on nonheterosexual and/or non-gender normative people. The term LGBT psychology signals a more unitary field than LGBT psychologies, the latter highlighting a multiplicity of psychological perspectives and also discrete bodies of psychological knowledge that focus on either lesbian, gay, bisexual, or transgender identities and topics (Clarke and Peel 2007). The epistemological frameworks and research methods utilized within the field of LGBT psychology differ between countries. In North America (and particularly the United States), positivist empiricism informed by liberal humanism is the dominant framework in this field (as with psychological 
Peel, E. \& Riggs, D.W. (2016) Lesbian, gay, bisexual, transgender psychologies. The Wiley Blackwell Encyclopedia of Gender and Sexuality Studies. (pp. 1-6) London: John Wiley. doi: 10.1002/9781118663219.wbegss137 (C) Cite Published Version, URL: http://onlinelibrary.wiley.com/doi/10.1002/9781118663219.wbegss 137/abstract

research more generally). In Europe and in Australasia, by contrast, LGBT psychological research is commonly more aligned with post-positivist and critical psychological traditions such as social constructionism. While recognizing these epistemic differences, the field may be epitomized as:

a branch of psychology that is affirmative of LGBTQ people. It seeks to challenge prejudice and discrimination against LGBTQ people and the privileging of heterosexuality in psychology and in the broader society. It seeks to promote LGBTQ concerns as legitimate foci for psychological research and promote non-heterosexist, non-genderist and inclusive approaches to psychological research and practice. It provides a range of psychological perspectives on the lives and experiences of LGBTQ people and on LGBTQ sexualities and genders. (Clarke et al. 2010,6)

Of note in this definition is the emphasis upon norms related to both sexual orientation and gender. LGBT psychology has increasingly paid attention to the differential effects of gender norms amongst individuals within the LGBT acronym. For example, attention has increasingly been paid to acknowledging the significant differences between lesbian women and gay men, or the differences between transgender people and cisgender people (i.e., people whose gender identity accords with that expected of their natally assigned sex). Increased recognition has also been paid within the field of LGBT psychology to the overlaps and differences between sexual orientation and gender identity, for example, research on gay transgender men, or research on gender differences within lesbian couples. As such, LGBT psychology as a field has increasingly moved toward an intersectional approach to identity, whereby attention is paid not simply to sexual orientation or gender identity, but rather to the intersections of a range of identities such as gender, class, race, sexual orientation, ability, and religion (see Clarke et al. 2010 for an overview and synthesis of the field).

\section{Historical overview}

A desire for positive social change, primarily on behalf of gay men and lesbian women, was the key driver in the establishment of what was first known as lesbian 
Peel, E. \& Riggs, D.W. (2016) Lesbian, gay, bisexual, transgender psychologies. The Wiley Blackwell Encyclopedia of Gender and Sexuality Studies. (pp. 1-6) London: John Wiley. doi: 10.1002/9781118663219.wbegss137 (C) Cite Published Version, URL: http://onlinelibrary.wiley.com/doi/10.1002/9781118663219.wbegss 137/abstract

and gay psychology. Until the development of the field, psychology (and allied sexological and psychiatric disciplines) had a long history of pathologizing, dehumanizing, and subjecting non-heterosexual and/or non-gender normative individuals to degrading and inappropriate treatment, such as aversion therapy. Before the 1970s, most psychological research focused on the question of whether or not homosexuals and transsexuals were sick, and how they could be cured. Early pioneers in "gay affirmative" psychology, such as Evelyn Hooker (1957), challenged the assumption of homosexual pathology that predominated within psychology, using positivist-empiricist scientific methods. Academic activists from the 1970s and 1980s fought to establish lesbian and gay psychology as a legitimate branch of the discipline of psychology.

Within the field that is now known as LGBT psychology itself, there have been ongoing debates over the most productive or appropriate modes of research. Kitzinger and Coyle (2002) argued that the field has been divided on the basis of what are seen as critical approaches, and what are seen as more mainstream approaches to psychological research. The former, it is suggested, seek to examine social norms including within psychology, whilst the latter accept the argument that psychological research is an exercise in discovering truths about the world. As the field has developed it has been increasingly recognized that both approaches have much to offer in terms of identifying and challenging social norms. This is perhaps nowhere more evident than in comparative research, which has dominated much of the field. While critiques have been made of comparative approaches (in that they assume that the experiences of LGBT people can only be understood when placed next to heterosexual and/or cisgender people), it can also be argued that comparative research highlights the effects of social norms that privilege heterosexual and cisgender people at the expense of LGBT people.

\section{Comparative approaches}

A comparative approach with regard to transgender people can assist in highlighting the health disparities arising from social norms relating to gender identity. Quantitative research on HIV prevalence, for example, suggests that transgender women who engage in sex work are more likely to contract HIV than are transgender 
Peel, E. \& Riggs, D.W. (2016) Lesbian, gay, bisexual, transgender psychologies. The Wiley Blackwell Encyclopedia of Gender and Sexuality Studies. (pp. 1-6) London: John Wiley. doi: 10.1002/9781118663219.wbegss137 @ Cite Published Version, URL: http://onlinelibrary.wiley.com/doi/10.1002/9781118663219.wbegss 137/abstract

women who do not engage in sex work, and both cisgender men and cisgender women who engage in sex work (Operario, Soma, and Underhill 2008). The reasons for this, it is suggested, are because of the high levels of vulnerability that transgender women are subjected to in terms of poverty and unemployment arising from transphobia. For instance, transgender women who engage in sex work may be more likely to engage in unprotected anal intercourse if clients offer additional payment for sex without protection.

Importantly, qualitative research with transgender women who engage in sex work highlights the complexities and intersectionalities that surround sex work for transgender women. Findings from a study of transgender women of color in the United States who engage in sex work (Sausa, Keatley, and Operario 2007) suggest two competing factors at play: (1) sex work as a "right of passage" for many transgender women (who may see sex work as a norm within transgender communities); and (2) sex work as a route to further marginalization (such as through clients encouraging drug use or unprotected intercourse). This research suggests that racism further compounds the latter factor, with transgender women of color's ability to "pass" as cisgender women (which, the authors suggest, may occur less readily than for white transgender women) impacting upon their ability to secure employment outside of sex work.

When considering gay (in this instance cisgender) men, comparative research focusing on parenting has usefully highlighted the specific experiences of gay fathers as they diverge from (and converge with) those of heterosexual fathers. For example, early US research by Bigner and Jacobsen (1989) compared 33 men who had their children in the context of a heterosexual relationship (but who at the time of the research identified as gay and continued to be involved in parenting their children), with 33 men who identified as heterosexual and who were fathers. Their research found that both groups reported similar levels of involvement and intimacy with their children. In terms of differences between the groups, the gay fathers tended to be more strict with their children, more responsive to their needs, and more consistent in their parenting style. A further notable point of difference was that the gay men suggested that having children enhanced their masculinity (in a context where 
Peel, E. \& Riggs, D.W. (2016) Lesbian, gay, bisexual, transgender psychologies. The Wiley Blackwell Encyclopedia of Gender and Sexuality Studies. (pp. 1-6) London: John Wiley. doi: 10.1002/9781118663219.wbegss137 (C) Cite Published Version, URL: http://onlinelibrary.wiley.com/doi/10.1002/9781118663219.wbegss 137/abstract

identifying as gay was often read as denoting femininity), and that being a father facilitated entrance and acceptance in the general (nominally heterosexual) community.

More recently, Farr, Forssell, and Patterson (2010) have investigated similarities and differences between lesbian, gay, and heterosexual coupled adoptive parents in the United States. In terms of similarities, the research found no significant differences between each group of adoptive parents on measures of child adjustment, parenting behaviors, or couple adjustment. In terms of differences, their research found small but significant differences wherein the children of lesbian or gay parents were described as having fewer behavioral problems than were the children of heterosexual parents. Looking at 230 US gay adoptive parents alone, Tornello, Farr, and Patterson (2011) found that unique to gay men as adoptive parents appears to be the role of sensitivity to stigma. Those men in their study who reported higher levels of sensitivity to gay-related stigma reported higher levels of parenting stress. These findings echo Bigner and Jacobsen's (1989) early research where gay men were concerned about effects of stigmatization.

A small body of comparative research has importantly highlighted the experiences of bisexual people in terms of mental health. In most LGBT psychology research, bisexual people are unfortunately too often grouped together with lesbians or gay men (Barker 2007). Such an approach fails to recognize the specific experiences of bisexual people as a population, and contributes to the widespread assumption that bisexuality is not a valid or true sexual identity. Such stigmatization and marginalization are examined in the work of Ross, Dobinson, and Eady (2010), whose qualitative study of bisexual Canadians found that the sample felt marginalized at multiple levels: by a society in general that discounts bisexual people; in interactions with friends and (non-bisexual) partners who demanded that they refuse a bisexual identity and instead identify as lesbian or gay; and within themselves, where they felt that the previous two forms of marginalization led them to question their own identity. 
Peel, E. \& Riggs, D.W. (2016) Lesbian, gay, bisexual, transgender psychologies. The Wiley Blackwell Encyclopedia of Gender and Sexuality Studies. (pp. 1-6) London: John Wiley. doi: 10.1002/9781118663219.wbegss137 (C) Cite Published Version, URL: http://onlinelibrary.wiley.com/doi/10.1002/9781118663219.wbegss 137/abstract

Quantitative research by Jorm and colleagues (2002) has found that the discrimination identified by Ross, Dobinson, and Eady (2010) potentially leads to higher rates of poor mental health amongst bisexual people, as compared to lesbians, gay men, and heterosexual people. Jorm and colleagues found that bisexual participants reported the lowest levels of mental health of all of the groups, and that bisexual people reported the highest levels of current adverse life events, and the least amount of support from family.

Comparative research on lesbian women has frequently been undertaken with respect to division of household labor and parenting. In regards to the former, empirical research from both the United States and United Kingdom has consistently found that lesbian couples more equally distribute household labor, as compared with both gay couples and heterosexual couples. Lesbian couples are more likely to either share household duties on an entirely equal basis, or to allocate tasks on the basis of interests or skills. Either way, research suggests that this is not necessarily differentiated by income (as is the case with gay and heterosexual couples, where the higher income earner typically does less of the household work). When it comes to parenting, again research has consistently found that, when compared with gay parents or heterosexual parents, lesbian mothers take relatively equal shares in providing care to children (Tasker and Golombok 1997). Importantly, however, and as Oerton (1998) suggests, these findings of equal distribution of labor within lesbian households should not be taken as representing something essential about lesbian women that results in their sharing of household duties and parenting tasks. Rather, what is most important to note is the obvious, namely that lesbian couples are composed of two women, both of whom will likely have been raised in a society where women are expected to be responsible for household work. That women in lesbian relationships are aware of this expectation, and are willing to negotiate with their partner to achieve positive and supportive outcomes for the relationship and family, is thus a product of lesbian women's negotiations of gender norms.

Taken together, it is clear that there is much mileage to be gained from the use of comparative approaches within the field of LGBT psychology, both between each of the groups subsumed by the acronym and between these groups (who are located 
Peel, E. \& Riggs, D.W. (2016) Lesbian, gay, bisexual, transgender psychologies. The Wiley Blackwell Encyclopedia of Gender and Sexuality Studies. (pp. 1-6) London: John Wiley. doi: 10.1002/9781118663219.wbegss137 (C) Cite Published Version, URL: http://onlinelibrary.wiley.com/doi/10.1002/9781118663219.wbegss 137/abstract

outside the norm) and the general (i.e., heterosexual cisgender) population (constituted as the norm).

\section{Intersectionality}

Research and theorizing in the field of LGBT psychology have increasingly paid attention to the issue of intersectionality. Such an approach argues that rather than focusing solely on one form of identity, it is important to examine how a range of differing identities intersect with one another to produce both privileges and disadvantages. Taking the examples of comparative research from above, we can see that transgender women are disadvantaged more so than cisgender women, but that all women are disadvantaged compared to men. Unpacking this further, we can see that transgender women of color constitute some of the most vulnerable women in Western societies.

Turning to look at lesbian mothers, whilst the findings of shared household duties and parenting responsibilities represent a hallmark of research on lesbian mothering, there are exceptions to this rule that are evident if we adopt an intersectional approach. For example, Sullivan's (1996) research on lesbian mothers suggests that class plays a significant role in determining the distribution of parental responsibilities, with working-class lesbian couples more likely to adhere to a more traditional model, with one of the women working and undertaking less of the household work, and one of the women being a stay-at-home mother taking the primary responsibility for the household. Australian research by Kentlyn (2006) suggests that although some lesbian couples may explicitly and publicly conform to such a traditional approach, gay couples are much more likely to engage in complex identity work to mask the nongender normative tasks undertaken by gay men. For example, Kentlyn suggests that gay men who take primary responsibility for cooking and cleaning (tasks traditionally allocated to women) may be represented publicly by their partner as hypermasculine (in order to combat the negative stigma attached to men who undertake such tasks).

Importantly, then, an intersectional approach highlights Oerton's (1998) claim that same-sex relationships are not gender-free. Rather, all people living in Western societies, regardless of their sexual orientation, exist in a relationship to social norms 
Peel, E. \& Riggs, D.W. (2016) Lesbian, gay, bisexual, transgender psychologies. The Wiley Blackwell Encyclopedia of Gender and Sexuality Studies. (pp. 1-6) London: John Wiley. doi: 10.1002/9781118663219.wbegss137 (C) Cite Published Version, URL: http://onlinelibrary.wiley.com/doi/10.1002/9781118663219.wbegss 137/abstract

and expectations about what it means to be a man or a woman, and indeed who is allowed to be a man or a woman. LGBT psychology has been at the forefront in terms of examining and identifying the mental health correlates of these expectations. As such, LGBT psychology has played an important role in identifying the negative impacts of social norms upon LGBT people, and in so doing continues to demonstrate that the issue at stake is not the level of pathology "inherent" to LGBT people (which, absent from discrimination, is no higher than the general population), but rather the detrimental impact of stigma and discrimination (Meyer 2003).

SEE ALSO: Cisgenderism; Heterosexism and homophobia; Intersectionality; Sexual identity and orientation; Transphobia

\section{References}

Barker, Meg. 2007. "Heteronormativity and the Exclusion of Bisexuality in Psychology.” In Out in Psychology: Lesbian, Gay, Bisexual, Trans and Queer Perspectives, edited by Victoria Clarke and Elizabeth Peel, 95-117. Chichester: John Wiley \& Sons.

Bigner, Jerry J., and R. Brooke Jacobsen. 1989. "The Value of Children to Gay and Heterosexual Fathers.” Journal of Homosexuality, 18: 167-172.

Clarke, Victoria, Sonja J. Ellis, Elizabeth Peel, and Damien W. Riggs. 2010. Lesbian, Gay, Bisexual, Trans and Queer Psychology: An Introduction. Cambridge: Cambridge University Press.

Clarke, Victoria, and Elizabeth Peel. 2007. "From Lesbian and Gay Psychology to LGBTQ Psychologies: A Journey in to the Unknown (or Unknowable)?” In Out in Psychology: Lesbian, Gay, Bisexual, Trans and Queer Perspectives, edited by Victoria Clarke and Elizabeth Peel, 11-35. Chichester: John Wiley \& Sons.

Farr, Rachel H., Stephen L. Forssell, and Charlotte J. Patterson. 2010. "Parenting and Child Development in Adoptive Families: Does Parental Sexual Orientation Matter?” Applied Developmental Science, 14: 164-178.

Hooker, Evelyn. 1957. "The Adjustment of the Male Overt Homosexual.” Journal of Projective Techniques, 21: 18-31.

Jorm, Anthony F., Ailsa E. Korten, Brian Rodgers, Patricia A. Jacomb, and Helen Christensen. 2002. "Sexual Orientation and Mental Health: Results from a 
Peel, E. \& Riggs, D.W. (2016) Lesbian, gay, bisexual, transgender psychologies. The Wiley Blackwell Encyclopedia of Gender and Sexuality Studies. (pp. 1-6) London: John Wiley. doi: 10.1002/9781118663219.wbegss137 @ Cite Published Version, URL: http://onlinelibrary.wiley.com/doi/10.1002/9781118663219.wbegss 137/abstract

Community Survey of Young and Middle-Aged Adults." British Journal of Psychiatry, 180: 423-427.

Kentlyn, Sue. 2006. “Adjusting Bass and Treble: The Continuously Modulated

Performance of Gender.” In Social Change in the 21st Century Conference 2006, October 27, QUT Carseldine, Brisbane.

Kitzinger, Celia, and Adrian Coyle. 2002. "Introducing Lesbian and Gay

Psychology.” In Lesbian and Gay Psychology: New Perspectives, edited by

Adrian Coyle and Celia Kitzinger, 1-29. Oxford: Blackwell.

Meyer, Ilan H. 2003. "Prejudice, Social Stress, and Mental Health in Lesbian, Gay, and Bisexual Populations: Conceptual Issues and Research Evidence." Psychological Bulletin, 129: 674-697.

Oerton, Sarah. 1998. "Reclaiming the 'Housewife'? Lesbians and Household Work." In Living "Difference": Lesbian Perspectives on Work and Family Life, edited by Gillian Dunne, 69-83. New York: Harrington Park Press.

Operario, Don, Toho Soma, and Kristen Underhill. 2008. "Sex Work and HIV Status among Transgender Women: Systematic Review and Meta-Analysis.” Journal of Acquired Immune Deficiency Syndromes, 48: 97-103.

Ross, Lori, Cheryl Dobinson, and Allison Eady. 2010. "Perceived Determinants of Mental Health for Bisexual People: A Qualitative Examination.” American Journal of Public Health, 100: 496-502.

Sausa, Lydia A., JoAnne Keatley, and Don Operario. 2007. "Perceived Risks and Benefits of Sex Work among Transgender Women of Color in San Francisco." Archives of Sexual Behaviour, 36: 768-777.

Sullivan, Maureen. 1996. "Rozzie and Harriet? Gender and Family Patterns of Lesbian Coparents." Gender \& Society, 10: 747-767.

Tasker, Fiona, and Susan Golombok. 1997. Growing Up in a Lesbian Family: Effects on Child Development. New York: Guilford Press.

Tornello, Samantha, Rachel Farr, and Charlotte J. Patterson. 2011. "Predictors of Parenting Stress among Gay Adoptive Fathers in the United States." Journal of Family Psychology, 25: 591-600.

\section{Further reading}


Peel, E. \& Riggs, D.W. (2016) Lesbian, gay, bisexual, transgender psychologies. The Wiley Blackwell Encyclopedia of Gender and Sexuality Studies. (pp. 1-6) London: John Wiley. doi: 10.1002/9781118663219.wbegss137 @ Cite Published Version, URL: http://onlinelibrary.wiley.com/doi/10.1002/9781118663219.wbegss 137/abstract

Clarke, Victoria, and Elizabeth Peel, eds. 2007. Out in Psychology: Lesbian, Gay, Bisexual, Trans and Queer Perspectives. Chichester: John Wiley \& Sons.

Riggs, Damien W., and Gordon Walker, eds. 2004. Out in the Antipodes: Australian and New Zealand Perspectives on Gay and Lesbian Issues in Psychology. Perth: Brightfire. 